\title{
CORRECTION
}

\section{Correction to: Timeliness of diagnosis and treatment: the challenge of childhood cancers}

Callum J. R. Mullen (D, Ronald D. Barr (D) and Eduardo L. Franco (D)

(C) The Author(s), under exclusive licence to Springer Nature Limited 2021

British Journal of Cancer (2021) 125:1178; https://doi.org/10.1038/s41416-021-01548-x

Correction to: British Journal of Cancer https://doi.org/10.1038/ s41416-021-01533-4, published online 1 September 2021

The original version of this article unfortunately contained a mistake in the legend of Fig. 1. Due to a typesetting error the legend incorrectly mentions "blue bars" although the figure appears in greyscale. We apologize for the error. The correct legend should read: "Fig. 1. Estimated incidence (numbers of cases, dark grey bars) of and mortality (numbers of deaths, light grey bars) from common paediatric cancers according to age group. A: 0-4, B: 5-9, C: 10-14, D: 15-19 years. Combined frequencies for males and females in 2020. Source: GLOBOCAN 2020 [14]. N.B.: GLOBOCAN omits data on sarcomas." The original article has been corrected. 